\title{
The Effects of Secondary Metabolites of Rangeland and Pasture Plants on the Animal Health in Mediterranean Ecological Conditions
}

\author{
Emre Kara and Mustafa Sürmen \\ Departmant of Field Crops, Faculty of Agriculture, Aydın Adnan Menderes University, Aydın 09100, Turkey
}

\begin{abstract}
Grazed areas including rangelands and pastures cover approximately 51\% of the Earth's continental surface. The plant species which are in these areas which form a wide biodiversity with living and non-living organisims, stand out with both as a forage source and medical use. In this natural habitat, plants are surrounded by a large number of potential enemies. Since plants are not able to escape from these enemies (herbivores and pathogenes), plants produce substances which are not functional for growing and develop but protect plants against external factors as defence mechanisms. These substances are called secondary metabolites. These substances which are seen differently from the primer metabolites, possess charachteristics specific to each plant species. Secondary metabolites of plant origin can be divided into three main groups as terpens, phenolic compounds and nitrogenous compounds. Terpenes have negative effects on many mammals and insects, because they are toxic. The lignin, a phenolic compound, is located in the plant cell wall and has a particularly digestibility-lowering effect. In addition, flavanoids, which are again phenolic compounds, are thought to be produced against harmful effects of UV rays and pathogen invasion. Tannins, another phenolic compounds, are generally toxic. When plants which have tannins are grazed by herbivorous, they significantly reduce chances of growth and survival of animals. Finally, the alkaloids which are in the nitrogenous secondary products, are seen in a very wide area. These metabolites, especially in invasive plants that are heavily exposed to heavy grazing rangelands and pastures, affect the nervous system in livestock and can cause paralysis and even sudden deaths These three secondary metabolite groups are also commonly found in plants that are not properly managed in the meadow and pasture areas of the Mediterranean climate zone and can cause economic damage by affecting animal health and quality of animal products, especially in areas where animal production is seen. However, these economic losses are not only due to the plant species but can change with the influence of environmental factors. Moreover, not every livestock is affected by the same damage, the damage threshold varies according to the livestock species. This situation affects the livestock sector and natural vegetation, which already have problems. If the rangelands and pastures we call quality and natural forage sources, are not properly managed, the grazing and other factors may lead to the increase of the plant species which affect to reduce the animal production and may cause the deterioration of the natural vegetation cover. In this study, many rangeland and pasture plants which are located in the Mediterranean climate zone and have different secondary metabolites have been examined and the positive and toxic effects on livestock health have been discussed. In addition, the proper management systems in the rangeland and pasture areas where these species are seen have been described and accordingly, possible changes in both animal production and natural vegetation have been mentioned if there is not properly managed. With rangeland and pasture improvement studies to be carried out in accordance with the information described here, both increase in animal production can be achieved and plants in these areas can contribute to the economy in terms of both medical and chemical substance possibilities.
\end{abstract}

Key words: Rangeland, secondary metabolites, toxic plants, animal health.

\section{Introduction}

Excessive and uncontrolled grazing causes the climax plant species to decrease and the vegetation to

Corresponding author: Emre Kara, M.Sc., Res. Asist., research fields: annual forage crops, forage quality, vegetation ecology. move away from its original compositions. Most of the plant communities of grassland and rangeland populations, most of which are invasive species, are composed of plants that are not lovingly and willingly eaten by animals, difficult to eat, and sometimes even plants that contain toxic substances [1]. These plants produce a wide variety of non-functional organic 
compounds during their growth and development. These substances are known as secondary metabolites [2]. Secondary metabolites were first described by the Nobel Prize-winner German biochemist Albrecht Kossel in 1891 as metabolites that have no vital role in the cell, unlike the primary metabolites. This definition is the corrected version of the definition previously used by Fredrich Czapek [3]. The secondary metabolites have a limited distribution in the plant kingdom. This property separates these compounds from the primary metabolites (amino acids, carbohydrates, oils). Primer metabolites are found in all individuals of the plant kingdom, while the secondary metabolites are often found only in a particular species or close species [2]. Over time, plants have developed different types defense mechanism against herbivores and pathogens as secondary metabolites (Tables 1 and 2). These metabolites, which are different from the primary metabolites, possess unique properties in every species. It feels like flowers and fruit that have each different smell and color. They have also contributed to the medical field for many years due to these reasons $[3,4]$.

The importance of adaptation of the secondary metabolites has not been known for many years. Previously, it was thought that the metabolism of these chemicals was end-products that were dysfunctional or in other words metabolic waste. Due to their importance in the context of pharmaceutical raw materials, poisons, sweeteners and industrial raw materials, organic chemists of the 19th and 20th centuries have turned to these compounds and thus have involved in the search for secondary metabolites [2]. Austrian scientist Anton Kerner von Marialun, who is an example of these researches, inspects the plant-insect interactions, but says that some materials, other than physical defense, inhibit insects and that plants survive. Later studies have found that any toxic plant does not affect all animals equally. As an example, it has been observed that Atropa belladonna fruids are not harmful to birds with deadly effects in ruminants [3]. A similar result is explained by the fact that camel and goats are more resistant to tannins than other ruminants [4].

In recent years it has been suggested that most herbicide metabolites have important ecological functions in plants. These functions include:

- Defense mechanism against herbivores, insects;

- Defense mechanism against fungus, bacteria and virus damage;

- The defense mechanism against light, water and other plants in competition for food;

- Intriguing signaling for seed distribution and pollination;

- Sending communication signals between the symbiotic microorganism and the plant;

- Protection mechanism against UV rays and other physical stresses [5].

\section{Secondary Metabolites}

There are three main groups: plant secondary metabolites, terpenes, phenolic and nitrogen compounds. These groups are chemically different from each other [2].

\subsection{Terpenes}

Terpenes or terpenoids form the broadest class of secondary products. Various compounds of this class are generally insoluble in water [2]. Because terpenes are toxic, they have a deterrent effect on many mammals

Table 1 The different types of secondary metabolites found in plants so far identified [6].

\begin{tabular}{ll}
\hline Secondary metabolites & Numbers determined in different types \\
\hline Terpenes & 6.410 \\
Alkaloids & 15.195 \\
Aromatic substances & 11.786 \\
Saponins & 3.464 \\
Tannins & 3.275 \\
\hline
\end{tabular}


Table 2 Some plants with glycosides found in rangelands in the Mediterranean climate zone [1].

\begin{tabular}{ll}
\hline Latin name & Glycosides \\
\hline Helleborus sp. & Hellebrin \\
Coronilla sp. & Coronillin \\
Rhododendron sp. & Ericolin, andromedotoxin \\
Cyclamen sp. & Cyclamin \\
Nerium oleander & Oleandrin, neriin, neriantin \\
Digitalis sp. & Digitalin, digitoxin, digoxinum \\
Anemone coranaria L. & Porotoanemonin, ranunculin \\
Adonis annua L. & Steroid and tritedpenoid glycosides, adonin, saponin \\
Agrostemma githago L. & Saponins, githagin \\
Arum maculatum L. & Saponin, arin \\
Galium aparine L. & Saponins \\
Equisetum arvense L. & Saponins \\
Xanthium strumarium & Xantostrumarin \\
Artemisia scoparia Waldst. Et & Taurisine \\
Artemisia santonicum L. & Taurisine \\
Anagalis arvensis L. & Cyclamin, saponin \\
Convolvulus arvensis L. & Convolvulin \\
Rumex sp. & Rumisin \\
Sinapis arvensis L. & Sinigrin, sinalpin \\
Cuscuta planiflora L. & Convolvulin \\
Ranunculus sp. & Ranunculin, protoanemonin \\
Digitalis ferruginea L. subsp. schischkinii (Ivan) Werner & Gitoxin, digitoxin, digoxin, digitalis \\
Solanum nigrum L. subsp. Nigrum & Solanidine \\
\hline
\end{tabular}

and insects fed on plants. For this reason they play an important role in plant defense [2]. They may reduce digestibility due to negative microbial effects [7]. Triterpenes which are active against vertebrate herbivors also include cardenolides and saponins. Cardenolides are glycosidic. Flavors are painful and highly toxic to highly organized animals [2].

Glycosides are compounds formed by the attachment of a sugar and a non-carbohydrate group by ester bonds, which are separated by an enzyme or by the action of dilute acids into a non-sugar moiety and one or more sugar molecules. The effect of some glycosides is that the enzymes in the digestive system of animals are the result of hydrolyzing these substances. When glycosides are hydrolyzed they are converted into toxic zionidic compounds [1]. Saponins are such name-borne steroids and triterpene glycosides due to their soap-like properties. Both the oil soluble and water-soluble elements in the molecular structure give detergent properties to the saponins and they foam like soap when they are shaken with water. Saponins can also affect sterol intake in the digestive tract or can lead to hemolysis after taking into circulating blood [2]. In addition, there are allelopathic, antimicrobial, and anti-insecticidal activities that reduce the digestibility of feed in ruminants [8].

Essential oils are also known as terpenoids and are known to fight unwanted rumen microbial activities. Essential oils are produced in many different parts of the plant such as flowers, leaves, fruits, bulbs, roots, seeds and trunk and changes in plant according to development period, plant health and environmental factors. Thymus and Origanum, rich in essential oils, significantly reduce methane release [9].

\subsection{Phenolic Compounds}

The plants produce a wide variety of secondary products bearing phenolic groups in the structure. These chemicals are classified as phenolic compounds herbal phenols are the chemical group in which about 
10,000 compounds are contained [2]. These compounds are present in plants in excess and protect plants against damages of insects and animals. In addition, the resulting products also lead to the formation of undesirable dark color in the fodder [1].

\subsubsection{Lignin}

It is the most abundant organic material in plants after cellulose: both primer and secondary function. Lignin is found in the walls of various delivery and supports tissue cells, primarily xylem trachea and woody tubular elements. The main secondary deposit can also be found in the peripheral wall of the primer wall and in the intact contact with cellulose and hemicellulose already present in the environment. It is known that it increases especially with maturation [8]. The mechanical rigidity of lignin strengthens the transmission texture and the body [10], growing upwards. And the negative pressure allows water and minerals to be transmitted through xylum without causing any collapse in the tissue. Such a key component in the water-bearing tissue must have made it one of the most important adaptive values that enable primitive plants to colonize in the terrestrial environment [2].

In addition to mechanical support, lignin plants have important protective properties. The physical endurance makes the lignin non-digestible for herbivores, while the plasticity plays a deterrent role in the feeding of animals. Lignin-bound cellulose and protein digestion are also reduced [2].

\subsubsection{Flavonoids}

It is one of the largest classes of plant phenols. It is thought that 500 million years ago plants represent the basis of colonization. It is assumed that it has emerged for pathogenic invasion and for harmful UV light effects. Except the geographical position, it changes depending on the type of plant, its phenological period, texture type. They are found in the epidermis cells [11].

Physiological functions are constantly discussed and the following conclusions are reached [11].

- To protect against insects and defending against microbes.

- Sun protection against UV radiation and severe light.

- To maintain the generation of the plant by attracting polinators with anthocyanin.

- To act like antioxidants.

- To influence the development of pollen.

- Developmental regulator, effective for oxine transfer.

They can be grouped like flavonol, flavone, flavanone, flavan-3-ol, isoflavone, and anthocyanin [11].

\subsubsection{Tannins}

In addition to lignins, it is the second class of herbal phenolic polymers in the advocacy category. They are divided into 2 types as condensed and hydrolyzable tannins. Condensed tannins are compounds formed by polymerization of flavonoid units. They are found frequently in woody plants. Hydrolyzable tannins are heterogeneous polymers containing mainly phenolic acids, including gallic acid, and simple sugars, smaller values than condensed tannins [2].

Tannins are generally toxic. Herbivorous significantly reduces the chances of their survival if they participate in their diet. Tannins prevent many animals from using plants as forage [2, 12]. In addition they may decrease the activity of ruminal microorganisms [6].

In addition to the negative effects of tannins, there are also positive features. As an anti-foaming agent, there is an anti-swelling effect in animals [8]. These tannins, especially in the genus Lotus, Astragalus and Onobrychis, are evaluated in rangelands with the inhibitory effect of swelling [12]. For example, it has been determined that the consumption of Lotus with $1-5 \mathrm{~g} / \mathrm{kg}$ of condensed granules has a lowering effect to prevent swelling [13]. It has also been mentioned that $20 \mathrm{~g} / \mathrm{kg}$ (DM) condensed tannin on Lotus pedunculatus strain has a beneficial effect [6].

Condensate tannins from forage tannins have been the subject of research because of their significant 
effects on ruminant yield and health. The effects of condensed tannins, which are known to be very beneficial and harmful, were indicated in Table 3.

Although the benefits are higher than the losses, the fact that it should be used is a matter to be emphasized. This also varies depending on the plant concentration and livestock species, particularly in the researches that the condensed tannins contained in the Lotus pedunculatus increase $10 \%$ milk yield [14]. At the same time Lotus corniculatus consumption has a positive effect on wool growth, live weight, milk yield due to condensed tannins [13, 15]. Again in a study, consumption of Lotus corniculatus with $44.5 \mathrm{~g} / \mathrm{kg}$ (DM) condensed tannins is indicated as a positive effect for milk yield [6].

\subsection{Nitrogen Seconder Products}

In the majority of herbal secondary metabolites, nitrogen is present. Among the compounds found in this group are alkaloids and cyanogenic glycosides, which are of great interest because of their toxicity and medical properties to humans. These compounds are also known as defensive elements against herbivors at the same time [2].

\subsubsection{Alkaloids}

It is a very large chemical group that is found in about $20 \%$ of vascular plant species [16]. And it can be found in different types of rangeland plants (Table 4.). It is also understood from the idea that a very important substance can actually cause dinosaurs to deplete [17]. It is thought that the reason for this is that the reptiles are 30 times more sensitive to alkaloids than the mammals and the dinosaurs have not developed their taste senses. However, recent research has revealed that birds are more similar to dinosaurs than reptiles and it is understood that the extinction of dinosaurs is not an alkaloid.

Alkaloids are generally classified as pyrrolizidine, tropane, piperidine, pyrolizidine, quinolizidin, isoquinoline alkaloids. Quinolizidin alkaloids are also called "lupine alkaloids" or "Papilonaceae alkaloids". This is due to the fact that such alkaloids have been isolated for the first time from Lupinus luteus seeds [18]. The function of alkaloids in plants is controversial for at least 100 years. Initially, alkaloids were thought to be nitrogenous waste, nitrogen storage compounds, or growth regulators. However, there was not even a small finding supporting these functions. Today, it is believed that because of its general toxicity and deterrent abilities, many alkaloids, especially mammals, act as defense components against hunters [2]. At the cellular level, the effect of alkaloids on animals is highly variable. Most of the alkaloids interact with nervous system elements, mainly chemical agents, while others affect transport of protein synthesis or the activities of various enzymes [2]. All the alkaloids seen in plants are not produced by plants themselves. Many pasture plants host endogenous fungal communities. These associates growing in the apoplast can synthesize a wide variety of alkaloids [2]. These associates, called mycotoxins, cause disorders in grazing animals. These metabolites, especially in the form of ergot alkaloids, such as Festuca arundinaceae Schreb. and Lolium perenne L., caused economic losses of only $\$ 500$ million to $\$ 1$ billion in US [12]. Four different mycotoxicities have

Table 3 Benefits and damages of condensed tannins in ruminants [14].

\begin{tabular}{ll}
\hline Benefits & Losses \\
\hline Increase live weight & High concentration reduces development. \\
Improving wool development & Difficulty in receiving forage in some condensed tannins \\
Increase birth rate & \\
Improving milk production in sheep and cow & \\
Increase protein in milk & \\
Anti-swelling protection & \\
Reduction of methane [6] & \\
\hline
\end{tabular}


Table 4 Some plants with alkaloids found in rangelands in the Mediterranean climate zone [1].

\begin{tabular}{ll}
\hline Latin name & Alkaloids \\
\hline Delphinium sp. & Delphinin, delphonin \\
Cicuta virosa & Cicitoxin \\
Conium maculatum & Conin, conicein, conihydrin \\
Atropa belladonna & Atropin \\
Colchicum sp. & Colchicin \\
Datura stramonium L. & Tporane (atropin), hyosiyamin, scoplamin \\
Echium vulgare L. & Pyrrolizidine (sinoglosin, kosolidin) \\
Senecio venalis L. & Pyrrolizidine, yakobin, yakonin, silvasenesin \\
Conium maculatum L. & Pyridine (coniine), metilkonin, koniserin \\
Centaurea iberica Trev. Ex sprengel Santaurin & Sianin, sikorin \\
Centaurea solstitialis L. subsp. solstitialis (L.) Lam & Santaurin, sianin, sikorin \\
Equisetum arvense L. & Equisetine \\
Adonis annua L. & Simarin, adonitoxin \\
Fumaria officinalis L. & Kriptokavin, fumarin \\
Papaver rhoeas L. & Isoquiroline, rhoeadin, rhoesin, tebain \\
Papaver commutatum Fisch. et Mey & Isoquiroline \\
Papaver argemone L. & Isoquiroline \\
Capsella bursa-pastoris L. & Bursin \\
Solanum dulcamara L. & Solanidine \\
Xanthium sp. & Xantostruman \\
\hline
\end{tabular}

been identified in farm animals due to fungal infections. Among them, ergot alkaloids, which are mostly mentioned above, are consumed by the livestock, resulting in the increase of live weight, adverse effects on fertility and even the deaths.

\subsubsection{Cyanogenic Glycosides and Glucosinolates}

In addition to alkaloids, plants also contain a variety of nitrogen containing protective compounds. Although these chemicals, which make up two groups of these compounds, are not toxic to themselves, their plants are not overwhelmed, they are immediately destroyed and emit toxic volatile poisons. However, with the enzyme-inhibiting effect, animals are at risk of shortness of breath, stroke or even death [12].

In particular, cyanogenic glycosides present in the species Trifolium repens L., together with the addition of grazing, make the white clover become indigestible [12]. Cynodon dactylon L. has been found to show an increase in cyanogenesis during the first developmental period, in particular to protect against herbivores [19].

\section{Some Rangeland and Pasture Plants of Mediterranean and Toxicity Effects [20-24]}

Lupins (Lupinus sp.): They contain alkaloids. Muscle fatigue, excitement and balance problems are signs of poisoning. It is seen in the coma due to sightlessness and sudden respiratory distress. However, in the absence of other plants, it is grazed. It has caused damages, birth problems, breathing problems, depression, ataxia, spasms, headache, coma, tremors.

Delphiniums (Delphinium sp.): They contain alkaloids. Muscle weakness and paralysis are seen. Resistance of cattle is less than that of other farm animals. Treatment can only be done quickly in animals that have been diagnosed: herbicides or ways to escape grazing with the sheep for biological fighting. It has caused damages: sudden death, weakness, impaired balance, swelling, unable to hold saliva.

Astragalus (Astragalus sp.): They contain alkaloids. Abnormal behaviors, abortion, heart problems, weight 
loss and poor performance are the basic symptoms. There is no cure.

Milkweeds (Asclepias sp.): They contain glycosides. It has the same toxicity as oleander. Abdominal pain, weakness, strangulation, lack of respiration and death are seen: depression, bad breath from the mouth, swelling, excessive saliva production, signs of poisoning. There is no cure. However, support therapies to be done in animals that are not very affected are useful. All animals may be affected. Sheep are most at risk, but cattle, goats, horses, poultry are also at risk. Primary toxicants are cardiac glycosides that cause gastrointestinal, cardiac and respiratory problems and can cause death if enough is consumed. Resins (especially galitoxin) in the milky sap may also contribute to the toxicity of milkweed. In ruminants, the first signs are incoordination, muscle tremors and spasms, bloat, increased heart rate, breathing problems, and occasionally death. Horses are very reluctant to eat this plant, and its toxicity is only rarely reported: colic, diarrhea, abnormal heart rate and rhythm, rarely death.

Poison hemlock (Conium maculatum): They contain alkaloids. It affects the nervous system within 1-2 hours. Heart rate irregularity is seen: low poisoning, sudden tremors and death. All animals may be affected. The toxic components include the volatile alkaloids coniine and gamma-conicine. Poison hemlock can also cause birth defects in ruminants.

Rygrasses (Lolium sp.): They contain ergot alkaloids. Neurological problems and tremors are signs of poisoning. Aggressiveness and impaired balance are seen. Without heavy poisoning, the animal suddenly falls down and can remain so for days. Lightly poisoned animal should be treated quickly with plenty of water and blood circulation should be renewed [25].

Tobacco (Nicotiana sp.): They contain alkaloids. Their poisoning properties are the same. Swinging, twitching, paralysis, shortness of breath, coma and death occur. Too much forage crops in rangeland is the best challenge

Choke cherry (Prunus virginiana): They contain cyanogenic glycosides. It blocks respiration. Sudden death can be seen. In hungry and hungry animals, a desire to eat occurs. Poisoned animal therapy is done with sodium nitrite and sodium thiosulfite. Cyanide prevents the body from being able to utilize oxygen at the cellular level, so although the animals physically can breath, their tissues and cells "suffocate". After consumption, signs will manifest within a few minutes, but sometimes up to an hour may pass. The animals will try to breath more rapidly and deeply, and then become anxious and stressed. Later, trembling, incoordination, attempts to urinate and defecate and collapse is noted, which can proceed to a violent death from respiratory and/or cardiac arrest within a few minutes to an hour. If an affected animal is still alive 2 or 3 hours after consumption, chances are good that it will live. Do not handle or stress affected animals any more than absolutely necessary, since this will worsen the signs. Also, affected animals are extremely stressed and may be dangerous to work with, therefore exercise caution so no human injury results.

Cocklebur (Xantium stramarium): They contain glycosides. Toxic content is more in developing plants. It is less harmful in 2-leaf period and seed. Cattle and sheep are affected. The consumption of $0.75 \%$ of the plant causes death: depression, weakness, loss of appetite, no movement, loss of balance muscle spasms.

Groundsel (Senecio sp.): They contain alkaloids. Lung disorders are seen. There is no cure. Tria jacobeae biological struggle is assessed.

St John's-wort (Hypericum sp.): It contains hypericin. It causes light sensitivity. They are signs of a tendency to escape from the sun or to hide. Antibacterial preparations can treat the damaged area. Cattle, sheep and goats are the most sensitive to this toxin. Animals must consume the plants for 4 to 5 days or more before clinical signs are noted. The affected skin first becomes swollen and tender, then reddened. This occurs primarily on the lightly pigmented areas (pink or white skin), and on the areas of the body that receive more sunlight (head, neck, back). The skin can 
be burned to the point where large areas of skin peel off. This is extremely painful, and predisposes the animal to infection.

Black nightshade (Solanum sp.): It contains solanine. Clinical signs of poisoning in the nightshade family tend to reflect gastrointestinal irritation and/or effects on the central nervous system. The plant is not palatable and is eaten only when animals have no other forage available. The plant may be a contaminant in hay, where it will still cause toxicity. Tannic acid and gastric lavage methods are used for early treatment

Hairy vetch (Vicia villosa L.): Aging, aggression, liver diseases are seen. Sodium nitrite and sodium thiosulfate are used for therapeutic purposes. Antibiotics are used to prevent second infections.

Jimsonweed (Datura stramonium): It contains atropine. Weakness, rapid pulse, enlarged pupils, shortness of breath, chills and coma are seen. Tannic acid and respiratory tract opener are used for the treatment. Even when forages are scarce, animals are reluctant to consume this plant. For animals, the danger lies primarily in the consumption of seeds that contaminate prepared feeds (hay, silage, grains, processed feeds). The plants may become palatable after the application of herbicides, thus greatly increasing the risk of toxicosis

Oleander (Nerium oleander): It contains alkaloids. Severe abdominal problems, diarrhea, sweating and fatigue are seen. There is no cure.

Sweet clover (Melilotus sp.); Internal bleeding is seen. All animals that eat affected hay may be poisoned. Clinical signs are related to the anticoagulant ("revents blood clotting” activity of dicoumarol (also called dicoumarin). Coumarin, present in sweet clover, is converted to dicoumarin during improper curing of sweet clover hay, or when the plant is excessively stressed (frosts, drought).

Johnson grass (Sorghum halepense): Difficulty in breathing, trembling and anxious expressions. It takes effect in 15-30 minutes. Sodium nitrite and sodium thiosulfate are the treatment methods.
Anemone (Anemone sp.): It contains ranunculin and anemonol. All parts of the plant are poisonous. When it dries, it can be grazed by animals. Clinical symptoms are the same in all animals. Common symptoms are mouth inflammation, irritability, salivation, vomiting, depression and poor pulse [26].

Spurge (Euphorbia sp.): It contains alkaloids, a glycoside, a dehydroxycoumarin and complex euphorbiosteroid. Symptoms are severe swelling of the mouth, salivation and diarrhea [26].

\section{Ways of Protecting against Toxic Effect of Plants}

Preventing animals from consuming too much of a poisonous plant in the first place is the best way to avoid livestock losses to poisonous plants. However, livestock grazing on rangeland generally cover large areas with a diverse array of plants. It is difficult, if not impossible, to prevent livestock from coming into contact with poisonous plants; however, following a few guidelines can minimize the likelihood of a severe loss to poisonous plants.

To protect your animals from poisoning:

- Learn to identify the poisonous plants that grow on your rangeland.

- Learn the conditions under which these plants can be dangerous to your livestock.

- Develop a grazing plan to improve your rangeland and prevent poisoning of your livestock by plants. Graze your rangelands at the proper time, and do not overgraze them.

- Do not allow animals that have been under stress or that are overly hungry to graze in areas infested with poisonous plants.

- Provide adequate water for your livestock.

- Be especially careful when grazing newly introduced livestock on your rangeland.

- Provide adequate salt and other supplements as needed.

- Control poisonous plants where feasible. 
- If your animals get sick, consult your veterinarian to ensure proper diagnosis and treatment. If a poisonous plant is involved, identification of the plant is essential for any corrective action [5].

\section{Results}

Plant secondary metabolites are products of great nature that have come up to date from ancient times. The importance of these secondary products produced by plants that do not have action especially against environmental conditions and harmful effects has not been understood so far. However, it is clear that these products, which are used in various religious rituals and medical problems, are actually a subject that needs to be examined in detail. Competition in grassland areas and heavy grazing has shown an increase in invasive species in vegetation cover. Without good rangeland management, the toxic secondary metabolites of the invasive species will be seen in larger areas. The proper pasture management, the protection areas to be created, the livestock farmers informed about these plants, and a national project on this subject will probably allow people in this subject to become more conscious. With work to be done, both increase in animal production can be achieved and plants in these areas can contribute to the economy in terms of both medical and chemical substance possibilities.

\section{References}

[1] Balabanl, C., Albayrak, S., Türk, M., and Yüksel, O. 2006. “Türkiye çayır meralarında bulunan bazı zararlı bitkiler ve hayvanlar üzerindeki etkileri.” Süleyman Demirel Üniversitesi Orman Fakültesi Dergisi, Seri: A, Sayı 2: 89-96.

[2] Taiz, L., and Zeiger, E. 2008. Plant Physiology, 3rd ed. Baskı, 285-307.

[3] Hartman, T. 2008. "The Lost Origin of Chemical Ecology in the Late 19th Century.” PNAS 105 (12): 4541-6.

[4] Acamovic, T., and Brooker, J. D. 2005. "Biochemistry of Plant Secondary Metabolites and Their Effects in Animals." Proceednigs of the Nutrition Society 64: 403-12.

[5] Wink, M. 2004. "Evolution of Toxins and Anti-nutritional Factors in Plants with Special Emphasis on Leguminosae.”
In Poisonous plants and related Toxins, Chapter 1, pp. 1-26.

[6] Rochfort, S., Parker, A. J., and Dunshea, F. R. 2008. "Plant Bioactives for Ruminant Health and Productivity." Phytochemistry 69: 299-322.

[7] Estell, R. E. 2010. "Coping with Shrub Secondary Metabolites by Ruminants.” Small Ruminant Research 94: 1-9.

[8] Dixon, R. A., and Sumner, L. W. 2003. "Legume Natural Products: Understanding and Maniplating Complex Pathways for Human and Animal Health.” Plant Physiol 131: 878-85.

[9] Patra, A. K. 2011. "Effects of Essential Oils on Rumen Fermentation, Microbial Ecology and Ruminant Production.” Asian Journal of Animal and Veterinary Advances 6 (5): 416-28.

[10] Baurhoo, B., Ruiz-Feria, C. A., and Zhao, X. 2008. "Purified Lignin: Nutritional and Health Impacts on Farm Animals-A Review.” Animal Feed and Technology 144: 175-84.

[11] Mouradov, A., and Spangenberg, G. 2014. "Flavonoids: a metabolic network mediating plants adaptation to their real estate.” Front. Plant Sci. 5:620 1-16.

[12] Mayland, H., and Cheeke, P. R. 1995. Forages, Volume 2. Edited by R. F. Barnes, D. A. Miller, and C. J. Nelson, 121-33.

[13] Mueller-Harvey, I. 2006. "Unravelling the Conundrum of Tannins in Animal Nutrition and Health.” Journal of the Science of Food and Agriculture 86: 2010-37.

[14] Waghorn, G. C., and McNabb, W. C. 2003. "Consequences of Plant Phenolic Compounds for Productivity and Health of Ruminants.” Proceedings of the Nutrition Society 62: 383-92.

[15] Aerts, R. J., McNabb, W. C., Molan, A., Brand, A., Barry, T. N., and Peters, J. S. 1999. "Condensed Tannins from Lotus cornicultasu and Lotus pedunculatus Exert Different Effects on the in Vitro Rumen Degradation of Ribulose-1,5-Biphosphate Carboxylase/Oxygenase (Rubisco) Protein.” Journal of the Science of Foed and Agriculture 79: 79-85.

[16] Cortinovis, C., and Caloni, F. 2015. “Alkaloid-Containing Plants Poisonous to Cattle and Horses in Europe.” Toxins 7: 5301-7.

[17] Swain, T. 1977. "Secondary Compounds as Protective Agents.” Ann. Rev. Plant Physiol. 28: 479-501.

[18] Tosun, A., and Özden, T. 1989. "Kinolizidin Alkaloitleri. Kimyasal Yapıları ve Biyolojik Aktiviteleri.” Pharmacia-JTPA 29 (63): 46-58.

[19] Cheeke, P. R. 1995. "Endogenous Toxins and Mycotoxins in Forage Grasses and Their Effects on Livestock.” $J$. Anim. Sci. 73: 909-18.

[20] Anonymous. 2017. Plant Poisoning of Livestock in Vermont. Date of access: 01.01.2017. 
https://www.uvm.edu/pss/vtcrops/articles/VTPoisonousPl ants.pdf.

[21] Anonymous. 2017. Guide to Toxic Plants in Forages. Date of access: 01.01.2017. https://www.extension.purdue.edu/extmedia/ws/ws_37_to xicplants08.pdf.

[22] Anonymous. 2017. Livestock Poisoning Plants of California. Date of access: 20.01.2017. http://anrcatalog.ucanr.edu/pdf/8398.pdf.

[23] Anonymous. 2017. Poisonous Plants of the Southern United States. Date of access: 20.01.2017. http://www.aces.edu/pubs/docs/A/ANR-0975/ANR-0975. pdf.
[24] Anonymous. 2017. "Plants Poisonous to Livestock on Western Rangelands.” Written by Mindy Pratt, Utah State University Extension. Date of access: 03.02.2017. http://articles.extension.org/pages/54951/plants-poisonou s-to-livestock-on-western-rangelands.

[25] Canty, M. J., Fogarty, U., Sheridan, M. K., Ensley, S. M., Schrunk, D. E., and More, S. J. 2014. "Ergot Alkaloid Intoxication in Perennial Ryegrass (Lolium perenne): An Emerging Animal Health Concern in Ireland." Irss Veterynary Journal 67 (21): 1-7.

[26] Cooper, M.R. and Johnson, A.W. 1984. "Poisonous plants in Britain and their effects of animals and man.” Ministry of Agric., Fishery and Food, 305. 